\title{
PENGARUH STRES KERJA DAN KOMPENSASI KARYAWAN TERHADAP TURNOVER INTENTION DENGAN LINGKUNGAN KERJA FISIK SEBAGAI MODERASI
}

\author{
Bertha Aprillyanti Jesiecca Worang ${ }^{1}$ \\ Ni Wayan Mujiati² \\ ${ }^{1,2}$ Fakultas Ekonomi dan Bisnis Universitas Udayana, Bali, Indonesia \\ email: worangbertha@yahoo.com
}

\begin{abstract}
ABSTRAK
Penelitian ini bertujuan untuk mengetahui pengaruh stres kerja dan kompensasi karyawan terhadap turnover intention dengan lingkungan kerja fisik sebagai variabel moderasi. Sampel penelitian ditetapkan sebanyak 147 responden dengan menggunakan teknik pengambilan sampel yaitu sampel jenuh. Teknik analisis yang digunakan adalah moderated regression analysis. Penelitian ini Pihak manajemen Hotel Mercure Legian-Bali harus tetap menurunkan stres kerja dan kompensasi karyawan di dalam perusahaan agar pegawai merasa aman dan nyaman dan dapat berkomitmen terhadap perusahaan, sehingga akan menurunkan turnover intention pada Hotel Mercure Legian-Bali. Hasil penelitian menunjukkan bahwa Stres kerja berpengaruh positif dan signifikan terhadap turnover intention Pada Hotel Mercure Legian-Bali. Kompensasi karyawan berpengaruh positif dan signifikan terhadap turnover intention Pada Hotel Mercure Legian-Bali. Lingkungan kerja fisik memoderasi berpengaruh Stres kerja terhadap turnover intention Pada Hotel Mercure Legian-Bali dan Lingkungan kerja fisik memoderasi berpengaruh kompensasi karyawan terhadap turnover intention Pada Hotel Mercure Legian-Bali.
\end{abstract}

Kata kunci: turnover intention, stres kerja, kompesasi karyawan, lingkungan kerja fisik

\begin{abstract}
This study aims to determine the effect of work stress and employee compensation on turnover intention with the physical work environment as a moderating variable. The research sample was determined as many as 147 respondents using a sampling technique that is saturated sample. The analysis technique used is moderated regression analysis. This research The management of the Mercure Legian-Bali Hotel must continue to reduce work stress and compensation of employees within the company so that employees feel safe and comfortable and can be committed to the company, so that it will reduce turnover intention at the Mercure Legian-Bali Hotel. The results showed that work stress had a positive and significant effect on turnover intention at the Mercure Legian-Bali Hotel. Employee compensation has a positive and significant effect on turnover intention at the Mercure Legian-Bali Hotel. The physical work environment moderates the effect of work stress on turnover intention at Mercure Legian-Bali Hotel and the physical work environment moderates the effect of employee compensation on turnover intention at the Mercure Legian-Bali Hotel.
\end{abstract}

Keywords: turnover intention, work stress, employee compensation, physical work environment 


\section{PENDAHULUAN}

Sumber daya manusia mempunyai peran utama dalam setiap kegiatan perusahaan Irvianti, \& Verina (2015), mengatakan bahwa munculnya intensi atau keinginan untuk meninggalkan organisasi merupakan pemicu awal terjadinya turnover yang menurut Mensah et al. (2015) dapat menjadi masalah serius bagi organisasi. Irvianti, \& Verina, (2015)mengatakan bahwa munculnya intensi atau keinginan untuk meninggalkan organisasi merupakan pemicu awal terjadinya turnover.

Dharma (2013) menyatakan bahwa turnover intention memiliki dampak negatif bagi organisasi karena dapat menciptakan ketidakstabilan terhadap kondisi tenaga kerja, menurunnya produktivitas karyawan, suasana kerja tidak kondusif dan juga berdampak pada meningkatnya biaya sumber daya manusia. Mustika \& Rahardjo (2017) menyatakan bahwa tenaga kerja atau sumber daya manusia dapat mempengaruhi perkembangan hotel dan ikut berperan dalam menjalankan aktivitas hotel.

Sianipar \& Haryanti (2014) menjelaskan tanda-tanda karyawan melakukan turnover intention adalah absensi yang meningkat, mulai malas bekerja, peningkatan pelanggaran terhadap tata tertib kerja karyawan, meningkatnya protes terhadap atasan dan perilaku positif yang sangat berbeda dari biasanya. Feng, (2016) menyatakan bahwa tidak mengherankan karyawan yang dibayar lebih banyak merasa puas dengan pekerjaan mereka dan kurang cenderung meninggalkan atasan mereka.

Subagyo (2014) menyatakan bahwa lingkungan kerja merupakan komponenkomponen dari dalam organisasi dan dari luar organisasi yang mempengaruhi organisasi dan merupakan komponen yang dapat dikendalikan dan sebagai komponen yang tidak dapat dikendalikan. Perusahaan harus memperhatikan lingkungan kerjanya, karena lingkungan kerja merupakan tempat aktivitas suatu pekerjaan dilakukan.

Iswara \& Sudharma (2013) menyatakan lingkungan kerja fisik yang memuaskan akan dapat meningkatkan gairah bekerja di dalam suatu organisasi, bekerja di lingkungan kerja yang mendukung secara optimal akan membantu mendorong tumbuhnya disiplin diri dalam bekerja menyatakan agar dapat mencapai tujuan, perusahaan harus menciptakan lingkungan kerja yang baik secara fisik dan non fisik.

Rumada \& Utama (2013) mengatakan bahwa keseluruhan dari faktor intern dan ekstern yang ada di sekitar tempat kerja setiap karyawan berupa tempat fisik seperti kursi, meja serta peralatan kerja lainnya yang dapat mempengaruhi karyawan di dalam melaksanakan tugas dan pekerjaannya sehari-hari disebut dengan lingkungan kerja fisik.

Arshadi \& Damiri (2013) menyatakan bahwa karyawan yang mengalami stres kerja lebih mungkin menjadi tidak sehat, kurang termotivasi, kurang produktif dan kurang merasa aman di tempat kerja. Menurut Qureshi et al. (2013) menyatakan 
informasi yang cukup tentang cara melakukan pekerjaan secara memadai dapat meredakan stres kerja yang dialami karyawan.

Stres kerja dapat berasal dari berbagai sumber dan mempengaruhi orangorang dengan cara yang berbeda. Tekanan pekerjaan yang berlebihan dapat menyebabkan karyawan merasa kurang puas dengan pekerjaannya sehingga mengalami stres dalam bekerja dan akhirnya menampikan kecenderungan karyawan memiliki keinginan untuk keluar dari perusahaan.

Swambawa, \& Rahyuda (2016), menyatakan bahwa mempertahankan karyawan merupakan tugas dan tanggung jawab perusahaan itu sendiri. Mehta, Kurbetti, \& Dhankhar (2014) dan Bibi et al. (2018), membuktikan bahwa kompensasi berpengaruh positif dan signifikan terhadap turnover intention. Adanya faktor dalam kompensasi yaitu karyawan masih ingin mencari hal-hal atau pengalaman baru, perihal adanya kompensasi yang diterima belum cukup bagi karyawan.

Stres kerja pada karyawan diakibatkan karena rasa bosan dengan adanya tanggung jawab untuk menyelesaikan tugasnya. Adanya keinginan karyawan untuk mendapatkan suasana dan pengalaman baru di tempat kerja lainnya yang menandakan kesetiaan karyawan rendah pada perusahaan. Jumlah karyawan yang keluar dari Hotel Mercure Legian-Bali pada tahun 2018 dapat dilihat sebagai berikut.

Tabel 1.

Data Turnover Karyawan Pada Hotel Mercure Legian-Bali Tahun 2017-2018

\begin{tabular}{cccc}
\hline \multirow{2}{*}{ Tahun } & $\begin{array}{c}\text { Jumlah Karyawan (orang) } \\
(\mathbf{1})\end{array}$ & $\begin{array}{c}\text { Karyawan Keluar } \\
\text { (orang) }\end{array}$ & $\begin{array}{c}\text { Persentase (\%) } \\
(\mathbf{3})\end{array}$ \\
\hline 2017 & 141 & $(\mathbf{2})$ & $\mathbf{( 2 )}: \mathbf{( 1 )} \mathbf{x} \mathbf{1 0 0}$ \\
2018 & 147 & 40 & 28,36 \\
\hline
\end{tabular}

Sumber: Data diolah, 2019

Prabawa \& Suwandana (2017) menyatakan perputaran karyawan dikatakan normal berkisar antara $5-10$ persen per tahun dan dikatakan tinggi apabila lebih dari 10 persen per tahun. Jika dilihat pada Tabel 1. pada tahun 2017 dari total jumlah karyawan 141 orang adalah 28,36 persen dan pada tahun 2018 dari total jumlah karyawan 147 orang adalah 18,36 persen. Berdasarkan hal tersebut, tingkat turnover karyawan pada Mercure Legian-Bali pada tahun 2017-2018 dapat dikatakan tinggi karena persentase per tahunnya adalah lebih dari 10 persen.

Ada beberapa indikator yang dapat mempengaruhi keinginan karyawan Hotel Mercure Legian-Bali untuk keluar dari organisasi yang berkaitan dengan stres kerja, kompensasi karyawan yang dimoderasi lingkungan kerja fisik. Berdasarkan latar belakang yang telah diuraikan dan melihat permasalahan dari Hotel Mercure Legian-Bali raih yang menyebabkan lingkungan kerja fisik akan memoderasi hubungan antara stres kerja dan turnover intention serta lingkungan kerja fisik akan memoderasi hubungan antara kompensasi kerja dan turnover intention. 
Stefhani \& Irvianti (2014) menyatakan bahwa para karyawan mengalami stres yang cukup mengganggu proses mereka dalam bekerja sehingga tingkat stres mereka perlu diminimalkan yang menyebabkan pengaruh stres kerja terhadap turnover intention tidak berpengaruh secara signifikan, dan setelah metode variabel stres kerja dihilangkan, menurut hasil kuesioner para karyawan cenderung mengalami stres kerja.

Qureshi et al. (2013) menyatakan bahwa pada industri tekstil di Pakistan menemukan stres kerja berhubungan secara positif terhadap turnover intention. Johartono \& Widuri (2013) menemukan bahwa stres kerja berpengaruh signifikan positif terhadap turnover intention.

Allisey et al. (2013) menyatakan bahwa terhadap lembaga kepolisian di Inggris mengidentifikasi bahwa stres kerja berpengaruh positif terhadap turnover intention. Arshadi \& Damiri (2013) menyatakan bahwa stres kerja memiliki hubungan positif dengan turnover intention. Suciati dkk. (2015) menunjukkan bahwa stres kerja berpengaruh positif terhadap turnover intention.

$\mathrm{H}_{1}$ : Stres Kerja berpengaruh positif terhadap Turnover Intention pada Hotel Mercure Legian, Bali

Hasil penelitian yang mendukung penelitian yang dilakukan oleh Putrianti, (2014) bahwa kompensasi berpengaruh negatif dan signifikan terhadap turnover intention karyawan. Tangthong et al. (2014) mengidentifikasi kompensasi sebagai faktor signifikan yang mempengaruhi niat karyawan untuk tinggal. Widayati \& Yunia (2016) menemukan bahwa kompensasi berpengaruh positif terhadap turnover intention, hal ini menunjukan bahwa semakin besar kompensasi yang diterima, niat untuk keluar dari pekerjaan akan berkurang karena karyawan merasa dihargai dengan kebutuhannya yang dapat terpenuhi, begitu juga sebaliknya.

Sandi (2014) mengungkapkan bahwa kompensasi berpengaruh negatif terhadap turnover intention. Devi \& Sudibia (2015) menyatakan bahwa kompensasi berpengaruh negatif terhadap turnover intention karyawan yang berarti bahwa semakin besar kompensasi yang diterima, niat untuk keluar dari pekerjaan akan berkurang karena karyawan merasa dihargai dengan kebutuhannya yang dapat terpenuhi, begitu juga sebaliknya.

$\mathrm{H}_{2}$ : Kompensasi berpengaruh negatif terhadap Turnover Intention pada Hotel Mercure Legian, Bali

Syahronica \& Ruhana (2015) menuyatakan bahwa stres merupakan faktor dominan yang mempengaruhi turnover intention. Irvianti \& Verina (2015) dalam penelitiannya menunjukkan stres kerja, dan lingkungan kerja secara parsial berpengaruh positif terhadap turnover intention.

Sahlan (2016) menunjukkan bahwa stres kerja karyawan perlu dikelola oleh seorang pimpinan perusahaan agar potensi-potensi yang merugikan perusahaan dapat diatasi. Dewi \& Wibawa (2016) menunjukkan bahwa tingkat stres kerja yang tinggikan berdampak pada turnover intention yang meningkat. Lingkungan pekerjaan fisik memberikan efek positif dari stres kerja yang tinggi terhadap turnover intention. 
Parvaiz et al. (2015) pun memberi petunjuk stres kerja mempunyai hubungan positif dengan turnover intention yang dimoderasi oleh lingkungan kerja fisik, bila pegawai mengalami stres kerja serta tak mempunyai mekanisme yang sesuai agar mengurangi stres kerja yang dipengaruhi oleh lingkungan kerja fisiknya.

$\mathrm{H}_{3}$ : Stres Kerja berpengaruh positif terhadap Turnover Intention yang dimoderasi oleh Lingkungan Kerja Fisik pada hotel Mercure Legian, Bali

Aarakit \& Kimbugwe (2015) mengatakan bahwa peran moderasi lingkungan kerja fisik pada hubungan kompensasi karyawan yang berpengaruh positif terhadap turnover intention. Khikmawati (2015) menyebutkan faktor lain yang signifikan negatif mempengaruhi turnover intention adalah lingkungan kerja. Penelitian Arliansyah (2016) juga memperlihatkan adanya pengaruh yang negatif antara kompensasi dan turnover intention yang di pengaruhi oleh lingkungan kerja fisik. Retno Khikmawati (2015) menyebutkan faktor lain yang signifikan negatif dimana faktor yang mempengaruhi turnover intention adalah lingkungan kerja fisik.

Putrianti (2014) yang membuktikan bahwa kompensasi berpengaruh negatif dan signifikan terhadap turnover intention. Hal ini didukung oleh penelitian Yunita (2015) yang menyebutkan turnover intention dipengaruhi secara signifikan oleh faktor lingkungan kerja. Oleh karena itu, untuk mengisi kesenjangan, penelitian ini mempertimbangkan lingkungan kerja sebagai moderator untuk menyelidiki lebih lanjut hubungan antara kompensasi dan turnover intention.

$\mathrm{H}_{4}$ : Kompensasi berpengaruh positif terhadap Turnover Intention yang dimoderasi oleh Lingkungan Kerja Fisik pada Hotel Mercure Legian, Bali.

\section{METODE PENELITIAN}

Desain penelitian ini menggunakan rancangan asosiatif. Penelitian asosiatif merupakan penelitian yang bertujuan untuk mengetahui pengaruh ataupun juga hubungan antara dua variabel atau lebih. Penelitian ini menguji Pengaruh Lingkungan Kerja Fisik Memoderasi Hubungan antara Stres Kerja dan Kompensasi terhadap Turnover Intention di Hotel Mercure Legian - Bali.

Lokasi penelitian ini dilakukan di Hotel Mercure Legian-Bali yang berada di J1. Raya Legian No.328, Legian, Kuta, Kabupaten Badung, Bali 80361 karena untuk mengetahui faktor mana yang mampu meningkatkan turnover intention di Hotel Mercure Legian-Bali dimana penelitian ini akan menguji Pengaruh Lingkungan Kerja Fisik Memoderasi Hubungan antara Stres Kerja dan Kompensasi terhadap Turnover Intention. Obyek dalam penelitian ini adalah Turnover Intention (Y), Stres Kerja (X1), Kompensasi (X2), dan Lingkungan Kerja Fisik (M).

Populasi dalam penelitian ini adalah seluruh karyawan Hotel Mercure Legian-Bali Metode penentuan responden dalam penelitian ini menggunakan Sampel Jenuh yang dimana semua jumlah responden yaitu sebanyak 147 orang digunakan sebagai responden dalam penelitian ini.

Penelitian ini menggunakan regresi berganda dengan Moderated Regression Analysis (MRA) untuk mengetahui pengaruh stres kerja dan kompensasi karyawan 
terhadap turnover intention dengan lingkungan kerja fisik sebagi variabel moderasi. Pengujian ini dilakukan untuk melihat signifikansi pengaruh individual dari variabel-variabel bebas dalam model terhadap variabel dependennya. Dengan melakukan pengujian ini nilai-nilai statistik setiap variabel bebas.

\section{HASIL DAN PEMBAHASAN}

Berdasarkan hasil penelitian yang dilakukan terhadap Hotel Mercure LegianBali dapat diketahui karakteristik respondennya meliputi jenis kelamin, usia, dan pendidikan terakhir yang dijelaskan pada Tabel 2.

Tabel 2. Deskripsi Responden Pada Hotel Mercure Legian-Bali

\begin{tabular}{ccccc}
\hline No & Variabel & Klasifikasi & $\begin{array}{c}\text { Jumlah } \\
\text { (orang) }\end{array}$ & $\begin{array}{c}\text { Persentase } \\
(\%)\end{array}$ \\
\hline \multirow{3}{*}{1} & Jenis & Laki - Laki & 79 & 53.74 \\
& Kelamin & Perempuan & 68 & 46.26 \\
& & Jumlah & 147 & 100 \\
& & 19-24 Tahun & 54 & 36.73 \\
3 & \multirow{2}{*}{ Usia } & 25-34 Tahun & 73 & 49.66 \\
& & 35-40 Tahun & 15 & 10.20 \\
& & $>40$ Tahun & 5 & 3.40 \\
& & & 147 & 100 \\
4 & \multirow{2}{*}{ Jumlah } & 15 & 10.20 \\
& Pendidikan & SMA & 68 & 46.26 \\
& terakhir & Diploma & 64 & 43.54 \\
& & S1 & 147 & 100 \\
\hline
\end{tabular}

Sumber: Data diolah, 2019

Tabel 2. menunjukkan jumlah karyawan Pada Hotel Mercure Legian-Bali yang di jadikan sampel sebanyak 147 orang. Jika di lihat dari jenis kelamin, jenis kelamin laki-laki mendominasi dalam penelitian ini dengan persentase sebesar 53,74 persen. Responden yang memiliki usia 25-34 tahun mendominasi dengan presentase sebesar 49,66 persen. Jika di lihat dari tingkat pendidikan yang memiliki tingkat pendiddikan terakhir diploma yang mendominasi dengan persentase sebesar 46,26 persen.

Uji validitas dilakukan dengan mengkorelasikan antara skor faktor dengan skor total dan bila korelasi tiap faktor tersebut bernilai positif $(\mathrm{r}>0,3)$, maka instrumen penelitian tersebut dapat dikatakan valid. Instrumen yang valid adalah instrumen yang dapat digunakan untuk mengukur apa yang seharusnya diukur. Tinggi rendahnya validitas menunjuk kan sejauh mana data yang terkumpul tidak menyimpang dari gambaran tentang variabel yang dimaksud. Hasil uji validitas penelitian ini ditunjukkan dalam Tabel 3. 
Tabel 3.

Hasil Uji Validitas Instrumen Penelitian

\begin{tabular}{lcccc}
\hline No & Variabel & Instrumen & $\begin{array}{c}\text { Pearson } \\
\text { Correlation }\end{array}$ & Keterangan \\
\hline \multirow{2}{*}{ 1. } & \multirow{2}{*}{ Stres kerja (X1) } & X1.1 & 0,918 & Valid \\
2. & Kompensasi Karyawan(X2) & X1.2 & 0,887 & Valid \\
& & X1.3 & 0,929 & Valid \\
& & X2.1 & 0,908 & Valid \\
& & X2.2 & 0,904 & Valid \\
3. & Lingkungan kerja fisik (M) & X2.4 & 0,944 & Valid \\
& & M1 & 0,895 & Valid \\
& & M2 & 0,937 & Valid \\
& & M3 & 0,893 & Valid \\
& & M4 & 0,930 & Valid \\
4. & Turnover intention $(\mathrm{Y})$ & Y2 & 0,915 & Valid \\
& & Y3 & 0,942 & Valid \\
& & & 0,912 & Valid \\
\hline
\end{tabular}

Sumber: Data diolah, 2019

Tabel 3. menunjukkan bahwa seluruh instrumen variabel penelitian berupa Stres kerja, kompensasi karyawan, lingkungan kerja fisik dan turnover intention telah memenuhi syarat uji validitas yang dimana nilai skor total Pearson Correlation masing-masing instrumen berada diatas 0,30 dan memiliki nilai signifikansi yang lebih kecil dari 5\% (0,05), maka instrumen layak digunakan menjadi alat ukur variabel-variabel tersebut.

Pengujian reliabilitas adalah suatu pengujian pada instrumen penelitian demi mendapatkan hasil bahwa instrumen yang digunakan dapat dipercaya dan diandalkan. Pengujian ini, nilai suatu reliabilitas ditunjukkan melalui skor Cronbach's Alpha yang dimana jika nilai skor tersebut berada diatas 0,60 maka instrumen tersebut dapat dikatakan reliabel. Hasil penelitian uji reliabilitas dapat dilihat pada Tabel 4.

Tabel 4.

Hasil Uji Reliabilitas Instrumen Penelitian

\begin{tabular}{llcc}
\hline No. & \multicolumn{1}{c}{ Variabel } & Cronbach's Alpha & Keterangan \\
\hline 1. & Stres kerja $(\mathrm{X} 1)$ & 0,893 & Reliabel \\
2. & Kompensasi Karyawan(X2) & 0,933 & Reliabel \\
3. & Lingkungan kerja fisik (M) & 0,938 & Reliabel \\
4. & Turnover intention $(\mathrm{Y})$ & 0,908 & Reliabel \\
\hline
\end{tabular}

Sumber: Data diolah, 2019 
Tabel 4. menunjukkan uji reliabilitas pada masing-masing variabel berada pada titik diatas 0,60 yang ditunjukkan pada hasil Cronbach's Alpha, maka dapat dikatakan seluruh instrumen telah memenuhi syarat reliabilitas atau kehandalan sehingga dapat digunakan untuk melakukan penelitian.

Variabel turnover intention pada penelitian ini merupakan variabel terikat. Variabel turnover intention yang disimbolkan dengan $\mathrm{Y}$ serta diukur dengan menggunakan 3 pernyataan yang ditanggapi menggunakan 5 poin Skala Likert.

\section{Tabel 5.}

Deskripsi Jawaban Responden terhadap Turnover intention

\begin{tabular}{|c|c|c|c|c|c|c|c|c|c|}
\hline \multirow{3}{*}{ No } & \multirow{3}{*}{ Pernyataan } & \multicolumn{5}{|c|}{ Proporsi Jawaban } & \multirow{3}{*}{ Jumlah } & \multirow{3}{*}{$\begin{array}{l}\text { Rata- } \\
\text { Rata }\end{array}$} & \multirow{3}{*}{ Kriteria } \\
\hline & & \multicolumn{5}{|c|}{$\begin{array}{c}\text { Responden } \\
\text { (orang) }\end{array}$} & & & \\
\hline & & 1 & 2 & 3 & 4 & 5 & & & \\
\hline 1 & $\begin{array}{l}\text { Saya berkeinginan untuk } \\
\text { mencari pekerjaan lain } \\
\text { Saya berkeinginan untuk }\end{array}$ & 19 & 7 & 25 & 43 & 53 & 545 & 3.71 & Baik \\
\hline 2 & $\begin{array}{l}\text { meninggalkan organisasi, } \\
\text { karena pekerjaan tidak } \\
\text { sesuai dengan keahlian }\end{array}$ & 21 & 11 & 33 & 53 & 29 & 499 & 3.39 & $\begin{array}{l}\text { Cukup } \\
\text { Baik }\end{array}$ \\
\hline 3 & $\begin{array}{l}\text { Saya akan meninggalkan } \\
\text { organisasi setelah } \\
\text { mendapatkan pekerjaan }\end{array}$ & 19 & 4 & 12 & 62 & 50 & 561 & 3.82 & Baik \\
\hline & & a-ra & & & & & & 3,64 & Baik \\
\hline
\end{tabular}

Sumber: Data diolah, 2019

Variabel turnover intention yang memiliki rata-rata terendah adalah pernyataan "Saya berkeinginan untuk meninggalkan organisasi, karena pekerjaan tidak sesuai dengan keahlian saya", diperoleh nilai rata-rata sebesar 3,39 yang masuk kriteria cukup baik, tetapi memiliki nilai rata-rata yang rendah dibandingkan dengan pernyataan yang lainnya ini berarti secara umum responden tertarik tidak berkeinginan untuk meninggalkan organisasi, karena pekerjaan sesuai dengan keahlian mereka.

Variabel turnover intention yang memiliki rata-rata tertinggi adalah pernyataan "Saya akan meninggalkan organisasi setelah mendapatkan pekerjaan yang lebih baik", diperoleh nilai rata-rata sebesar 3,82 yang masuk kriteria baik, ini berarti secara umum responden merasa akan meninggalkan organisasi setelah mendapatkan pekerjaan yang lebih baik.

Variabel stres kerja pada penelitian ini merupakan variabel bebas. Variabel Stres kerja yang disimbolkan dengan X1 serta diukur dengan menggunakan 4 pernyataan yang ditanggapi menggunakan 5 poin Skala Likert. 
Variabel Stres kerja yang memiliki rata-rata terendah adalah pernyataan "Saya merasa resah dengan adanya persaingan yang tidak sehat diantara rekan kerja.", diperoleh nilai rata-rata sebesar 3,39 yang masuk kriteria cukup baik, tetapi memiliki nilai rata-rata yang rendah dibandingkan dengan pernyataan yang lainnya ini berarti secara umum responden menganggap merasa resah dengan adanya persaingan yang tidak sehat diantara rekan kerja.

Variabel Stres kerja yang memiliki rata-rata tertinggi adalah pernyataan "Saya menghabiskan seluruh waktu saya untuk menyelesaikan pekerjaan", diperoleh nilai rata-rata sebesar 3,79 yang masuk kriteria baik, ini berarti secara umum responden menganggap menghabiskan seluruh waktu mereka untuk menyelesaikan pekerjaan.

\section{Tabel 6.}

Deskripsi Jawaban Responden terhadap Stres kerja

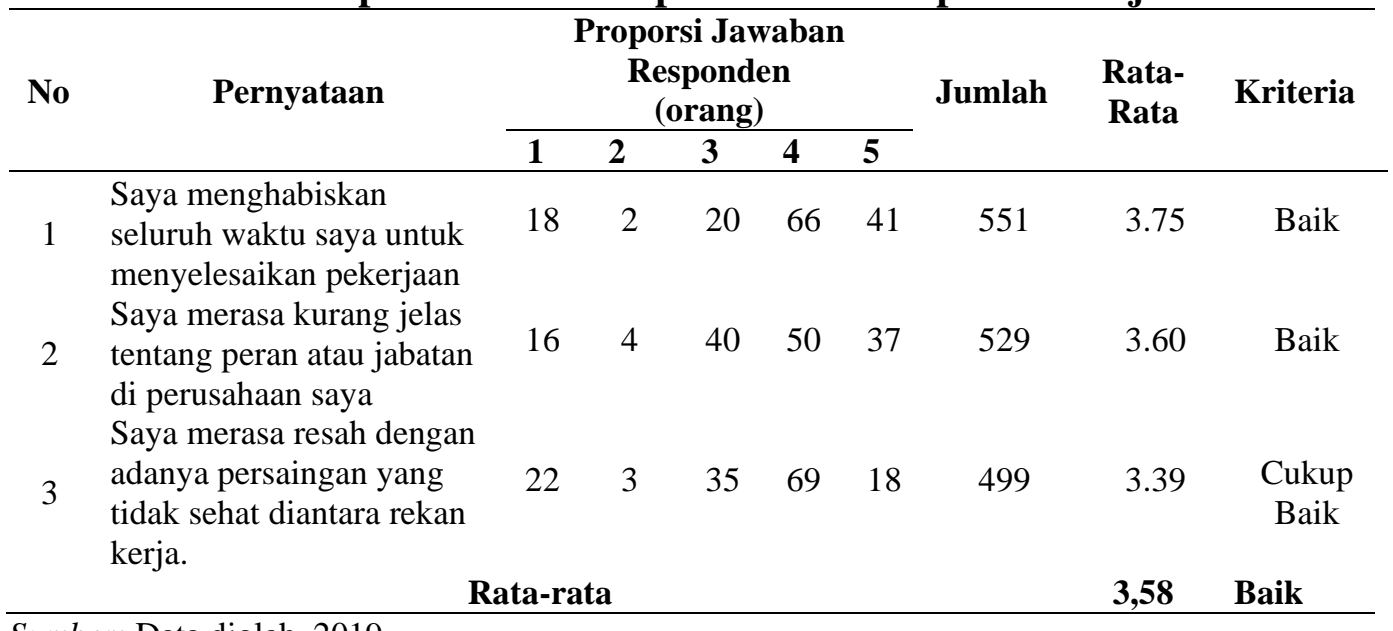

Sumber: Data diolah, 2019

Variabel kompensasi karyawan pada penelitian ini merupakan variabel bebas. Variabel kompensasi karyawan yang disimbolkan dengan X2 serta diukur dengan menggunakan 4 pernyataan yang ditanggapi menggunakan 5 poin Skala Likert.

Variabel kompensasi karyawan yang memiliki rata-rata terendah adalah pernyataan "Saya mendapatkan gaji sesuai dengan hak atas pekerjaan yang saya", diperoleh nilai rata-rata sebesar 3,39 yang masuk kriteria cukup baik, tetapi memiliki nilai rata-rata yang rendah dibandingkan dengan pernyataan yang lainnya ini berarti secara umum responden menganggap belum mendapatkan gaji sesuai dengan hak atas pekerjaan mereka.

Variabel kompensasi karyawan yang memiliki rata-rata tertinggi adalah pernyataan "Saya selalu menerima tunjangan dari perusahaan", diperoleh nilai ratarata sebesar 3,80 yang masuk kriteria baik, ini berarti secara umum responden menganggap selalu menerima tunjangan dari perusahaan. 
Variabel lingkungan kerja fisik pada penelitian ini merupakan variabel moderasi. Variabel lingkungan kerja fisik yang disimbolkan dengan M serta diukur dengan menggunakan 4 pernyataan yang ditanggapi menggunakan 5 poin Skala Likert.

Variabel lingkungan kerja fisik yang memiliki rata-rata terendah adalah pernyataan "Kebersihan dalam lingkungan kerja membuat saya nyaman dalam bekerja", diperoleh nilai rata-rata sebesar 3,37 yang masuk kriteria baik, tetapi memiliki nilai rata-rata yang rendah dibandingkan dengan pernyataan yang lainnya ini berarti secara umum responden menganggap Kebersihan dalam lingkungan kerja belum membuat mereka nyaman dalam bekerja.

Tabel 7.

Deskripsi Jawaban Responden terhadap kompensasi karyawan

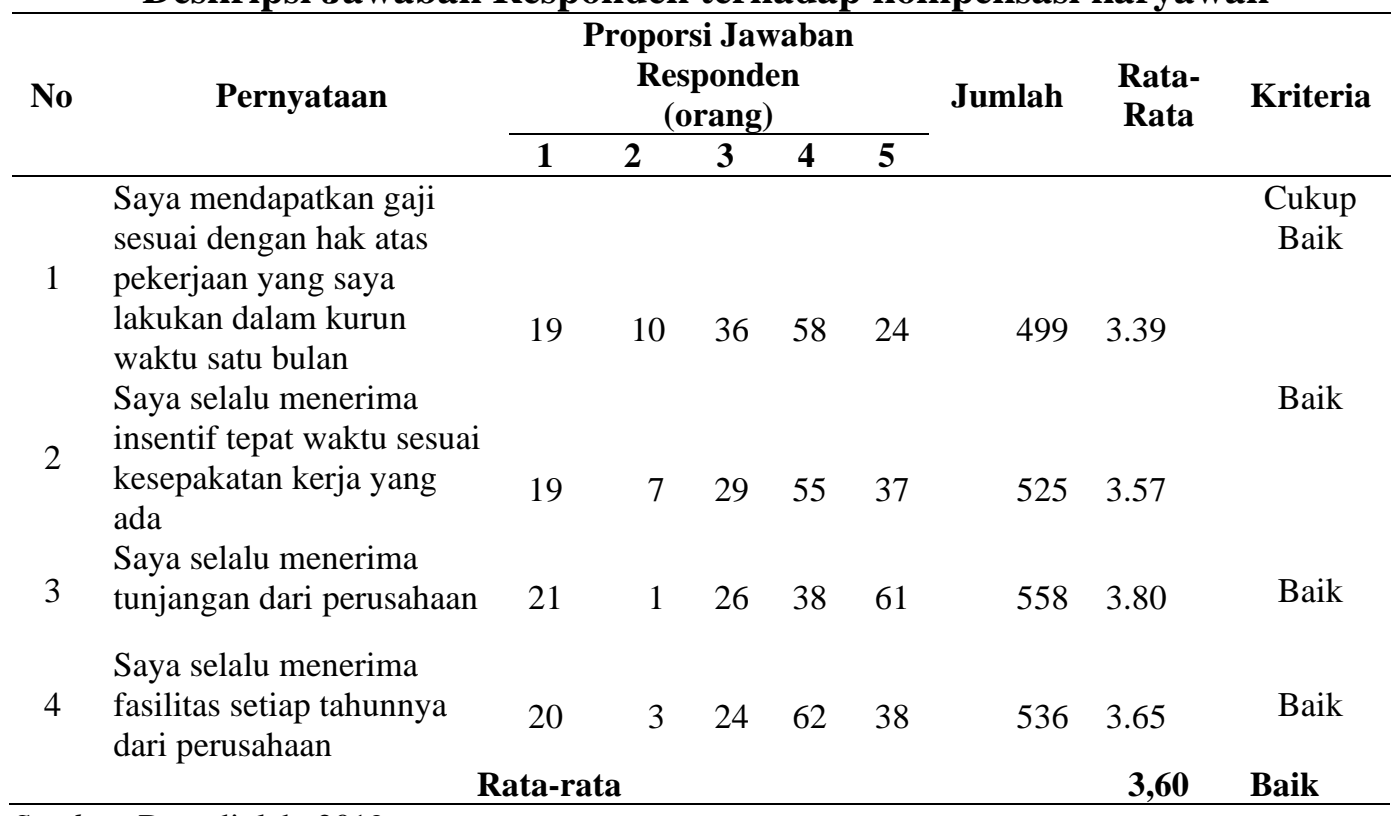

Sumber: Data diolah, 2019

Variabel lingkungan kerja fisik yang ditempat kerja saya sudah nyaman untuk bekerja", diperoleh nilai rata-rata sebesar 3,66 memiliki rata-rata tertinggi adalah pernyataan "Suhu udara yang masuk kriteria baik, ini berarti secara umum responden menganggap Suhu udara ditempat kerja sudah nyaman untuk bekerja.

Analisis derteminasi dilakukan untuk mengetahui sejauh mana variasi variabel bebas yaitu X1 (stress kerja), X2 (Kompensasi karyawan) dan M (lingkungan kerja fisik) terhadap variabel turnover intention (Y) Berdasarkan hasil spss yang dapat dilihat pada Tabel 8. 
Tabel 8. menunjukkan bahwa nilai $r$ square $\left(\left(r^{2}\right)=0,630\right.$ Adapun analisis menggunakan rumus berikut :

$$
\begin{aligned}
& D=r^{2} \times 100 \% \ldots \ldots \\
& D=0,630 \times 100 \% \\
& D=63 \%
\end{aligned}
$$

Hasil tersebut diketahui bahwa nilai $\mathrm{R}^{2}=63$ persen, yang berarti bahwa sebesar 63 persen turnover intention pada Hotel Mercure Legian-Bali dipengaruhi oleh variabel strees kerja, kompensasi karyawan dan lingkungan kerja fisik dan sisanya sebesar 37 persen dipengaruhi oleh variabel lain yang tidak diteliti pada penelitian ini.

Penelitian ini pengujian normalitas dilakukan menggunakan analisis analisis statistik One-Sample Kolmogorov-Smirnov, yaitu dengan membandingkan Kolmogorov-Smirnov hitung dengan Kolmogorov-Smirnov tabel. One-Sample Kolmogorov-Smirnov pada uji non parametrik.Adapun hasil uji One-Sample Kolmogorov-Smirnov dapat ditampilkan dalam Tabel 8.

Tabel 8.

Deskripsi Jawaban Responden terhadap Lingkungan kerja Fisik

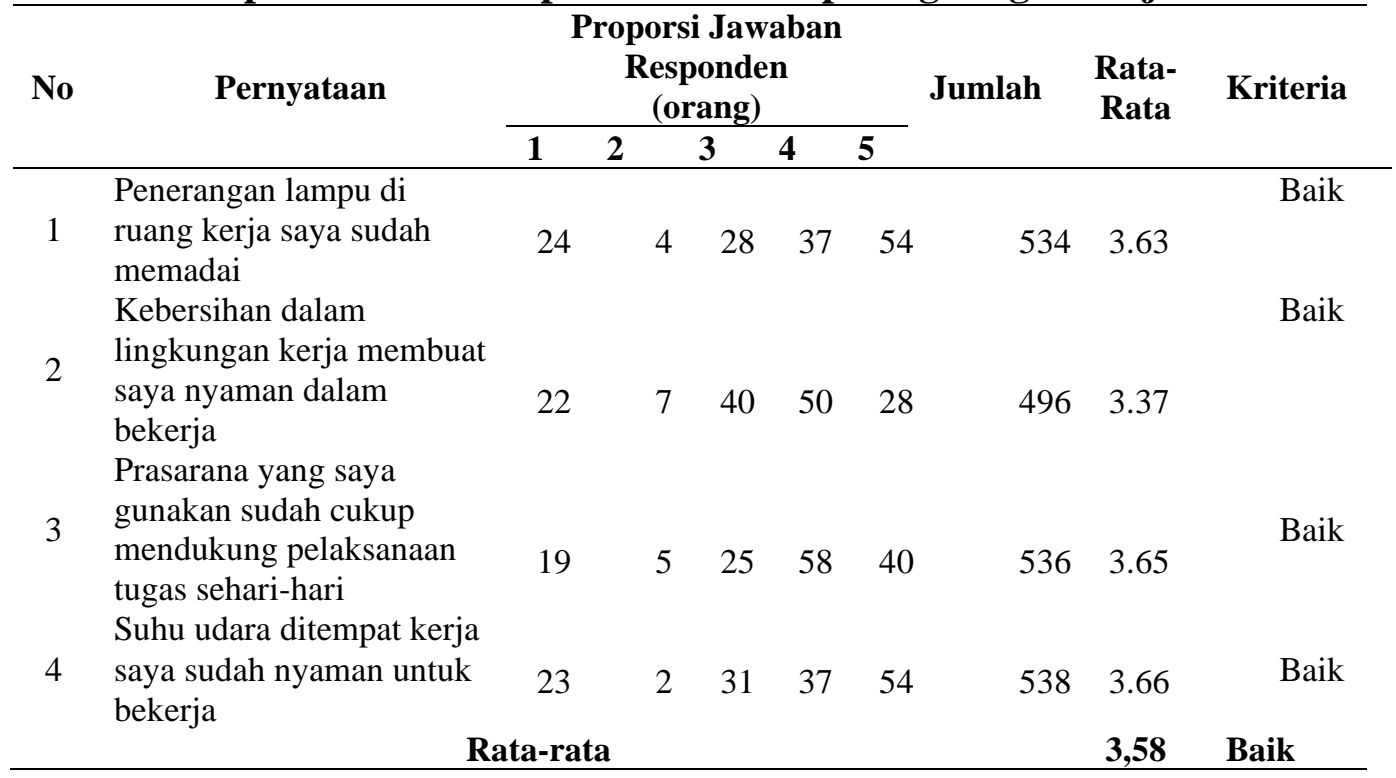

Sumber: Data diolah, 2019

Tabel 9.

Analisis Determinasi 
E-Jurnal Manajemen, Vol. 9, No. 5, 2020 : 1758-1777

\begin{tabular}{lrrrr}
\hline Model & R & R Square & Adjusted R Square & \multicolumn{2}{c}{$\begin{array}{c}\text { Std. Error of the } \\
\text { Estimate }\end{array}$} \\
\hline 1 & $0.794^{\mathrm{a}}$ & 0.630 & 0.617 & 1.682 \\
\hline
\end{tabular}

Sumber : Lampiran 6 Data primer (data diolah), 2019

Uji pada Tabel 10. bertujuan untuk menguji apakah pada model regresi ditemukan adanya korelasi antar variabel bebas. Jika nilai tolerance lebih dari 10\% atau VIF kurang dari 10, maka dapat dikatakan tidak ada multikolinieritas.

Tabel 10.

Uji Normalitas (One-Sample Kolmogorov-Smirnov)

\begin{tabular}{|c|c|c|}
\hline & & $\begin{array}{c}\text { Unstandardized } \\
\text { Residual }\end{array}$ \\
\hline $\mathrm{N}$ & & 147 \\
\hline \multirow{3}{*}{ Normal Parameters ${ }^{\mathrm{a}, \mathrm{b}}$} & Mean & .000 \\
\hline & Std. Deviation & 1.60792178 \\
\hline & Absolute & .097 \\
\hline \multirow[t]{2}{*}{ Most Extreme Differences } & Positive & .097 \\
\hline & Negative & -.072 \\
\hline Kolmogorov-Smirnov Z & & 1.182 \\
\hline Asymp. Sig. (2-tailed) & & .122 \\
\hline
\end{tabular}

Tabel 11.

Uji Multikolinieritas

\begin{tabular}{lcccc}
\hline Model & \multicolumn{3}{c}{ Collinearity Statistics } \\
& \multicolumn{3}{c}{ Tolerance } & VIF \\
\hline \multirow{2}{*}{1} & $\mathrm{X} 1$ & .685 & 1.460 \\
& $\mathrm{X} 2$ & .685 & 1.460 \\
\hline
\end{tabular}

Sumber: Lampiran 7 (data diolah), 2019

Tabel 11. menunjukkan nilai tolerance dan VIF dari variabel stres kerja dan kompensasi karyawan. Nilai tersebut menunjukkan bahwa nilai tolerance untuk setiap variabel lebih besar dari 10 persen dan nilai VIF lebih kecil dari 10 yang berarti model persamaan regresi 1 bebas dari multikolinieritas.

Pengujian heteroskedastisitas diakukan melalui metode glesjer dan dengan grafik scatterplot. Metode glesjer meregresikan model regresi untuk mendapatkan nilai residualnya, kemudian nilai residual tersebut diabsolutkan dan dilakukan regresi dengan semua variabel independen. Bila terdapat variabel independen yang berpengaruh secara signifikan terhadap residual absolut maka terjadi heteroskedastisitas pada model regresi ini.Tabel 12. menunjukkan hasil perhitungan statistik dengan metode glesjer. 
Tabel 12. menunjukkan bahwa masing-masing model memiliki nilai signifikansi lebih besar dari 5\%. Hal ini menunjukkan bahwa variabel bebas yang digunakan pada penelitian ini tidak berpengaruh secara signifikan terhadap variabel terikatnya yaitu absolute error, maka dari itu, penelitian ini bebas dari gejala heteroskedastisitas.

Tabel 12.

Uji Heteroskedastisitas (Uji Glesjer) Coefficients(a)

\begin{tabular}{|c|c|c|c|c|c|c|}
\hline \multirow{2}{*}{\multicolumn{2}{|c|}{ Model }} & \multicolumn{2}{|c|}{ Unstandardized Coefficients } & \multirow{3}{*}{$\begin{array}{l}\text { Standardized } \\
\text { Coefficients } \\
\text { Beta }\end{array}$} & \multirow{3}{*}{$\begin{array}{l}\mathbf{t} \\
\mathbf{5 . 4 5 2}\end{array}$} & \multirow{3}{*}{$\begin{array}{l}\text { iig. } \\
.000 \\
\end{array}$} \\
\hline & & B & Std. Error & & & \\
\hline \multirow{3}{*}{1} & (Constant) & 1.920 & .352 & & & \\
\hline & $\mathrm{X} 1$ & -.040 & .042 & -.092 & -.935 & .351 \\
\hline & $\mathrm{X} 2$ & -.038 & .031 & -.122 & -1.230 & .221 \\
\hline
\end{tabular}

Sumber : Lampiran 7 Data primer (data diolah), 2019

Pada penelitian ini digunakan teknik Uji Interaksi (Moderated Regression Analysis) merupakan aplikasi khusus regresi berganda linear, dalam persamaan regresinya mengandung unsur interaks. Pengaruh hubungan kausalistik masingmasing variabel yang terdiri dari stres kerja, kompensasi karyawan, dan lingkungan kerja fisik terhadap turnover intention. Pada penelitian ini dihitung pengaruh Stres kerja, kompensasi karyawan dan lingkungan kerja fisik terhadap turnover intention melalui program SPSS 21.0 for windows pada Tabel 13.

Tabel 13.

Hasil Moderated Regression Analysis

\begin{tabular}{|c|c|c|c|c|c|c|}
\hline \multirow[t]{2}{*}{ Model } & & \multicolumn{2}{|c|}{ Unstandardized Coefficients } & \multirow{2}{*}{$\begin{array}{c}\begin{array}{c}\text { Standardized } \\
\text { Coefficients }\end{array} \\
\text { Beta }\end{array}$} & \multirow[t]{2}{*}{$\mathbf{t}$} & \multirow[t]{2}{*}{ Sig. } \\
\hline & & B & Std. Error & & & \\
\hline \multirow{3}{*}{1} & (Constant) & .873 & .508 & & 1.717 & .088 \\
\hline & $\mathrm{X} 1$ & .484 & .061 & .471 & 7.914 & .000 \\
\hline & $\mathrm{X} 2$ & .328 & .044 & .441 & 7.400 & .000 \\
\hline
\end{tabular}

Sumber: Data diolah, 2019

Hasil pada Tabel 13. menunjukkan bahwa hasil hubungan XI dan X2 ke variabel Y sebesar 0,000 .

Hasil pada Tabel 14. menunjukkan bahwa hasil hubungan XI ke variabel M sebesar 0,000 serta hubungan X2 ke variabel M sebesar 0,006 maka dapat dirumuskan persamaan struktural yang terbentuk adalah sebagai berikut.

$$
\mathrm{Y}=\beta 1 \mathrm{X} 1+\beta 2 \mathrm{X} 2+\beta 3 \mathrm{X} 1 \mathrm{M}+\beta 4 \mathrm{X} 2 \mathrm{M}+e
$$




$$
\mathrm{Y}=0,518 \mathrm{X} 1+0,422 \mathrm{X} 2+0,036 \mathrm{X} 1 \mathrm{M}+0,020 \mathrm{X} 2 \mathrm{M}
$$

Hasil hipotesis dalam penelitian ini menunjukkan bahwa stres kerja berpengaruh positif dan signifikan terhadap turnover intention dengan kata lain semakin meningkat stres kerja maka turnover intention pada Hotel Mercure LegianBali akan semakin meningkat, sehingga hipotesis pertama diterima.

Hal ini sejalan dengan hasil penelitian yang dilakukan oleh Stefhani \& Irvianti (2014), menyatakan bahwa para karyawan mengalami stres yang cukup mengganggu proses mereka dalam bekerja sehingga tingkat stres mereka perlu diminimalkan yang menyebabkan pengaruh stres kerja terhadap turnover intention tidak berpengaruh secara signifikan, dan setelah metode variabel stres kerja dihilangkan, menurut hasil kuesioner para karyawan cenderung mengalami stres kerja. Qureshi et al. (2013) menyatakan bahwa pada industri tekstil di Pakistan menemukan stres kerja berhubungan secara positif terhadap turnover intention.

Tabel 14.

Hasil Moderated Regression Analysis (MRA) X1, X2, X1M dan X2M

\begin{tabular}{|c|c|c|c|c|c|c|}
\hline \multirow{2}{*}{\multicolumn{2}{|c|}{$\begin{array}{l}\text { Model } \\
\text { nol }\end{array}$}} & \multicolumn{2}{|c|}{ Unstandardized Coefficients } & \multirow{2}{*}{$\begin{array}{c}\begin{array}{c}\text { Standardized } \\
\text { Coefficients }\end{array} \\
\text { Beta }\end{array}$} & \multirow[t]{2}{*}{$\mathbf{t}$} & \multirow[t]{2}{*}{ Sig. } \\
\hline & & B & Std. Error & & & \\
\hline \multirow{5}{*}{1} & (Constant) & 1.540 & .582 & & 2.648 & .009 \\
\hline & $\mathrm{X} 1$ & .518 & 249 & .183 & 2.081 & .039 \\
\hline & $\mathrm{X} 2$ & .422 & .098 & .566 & 4.286 & .000 \\
\hline & $\mathrm{X} 1 \mathrm{M}$ & .036 & .007 & .696 & 5.515 & .000 \\
\hline & $\mathrm{X} 2 \mathrm{M}$ & .020 & .007 & .514 & 2.803 & .006 \\
\hline
\end{tabular}

Johartono \& Widuri (2013) menemukan bahwa stres kerja berpengaruh signifikan positif terhadap turnover intention. Allisey et al. (2013) menyatakan bahwa terhadap lembaga kepolisian di Inggris mengidentifikasi bahwa stres kerja berpengaruh positif terhadap turnover intention. Arshadi \& Damiri (2013) menyatakan bahwa stres kerja memiliki hubungan positif dengan turnover intention. Suciati dkk. (2015) menunjukkan bahwa stres kerja berpengaruh positif terhadap turnover intention.

Hasil hipotesis dalam penelitian ini menunjukkan bahwa kompensasi karyawan memiliki pengaruh positif dan signifikan terhadap turnover intention, dengan kata lain apabila kompensasi karyawan meningkat maka turnover intention pada Hotel Mercure Legian-Bali. akan semakin meningkat, sehingga hipotesis kedua diterima.

Hal ini sejalan dengan Penelitian yang dilakukan Hasil penelitian yang mendukung penelitian yang dilakukan oleh Putrianti (2014). Widayati \& Yunia (2016) dan Parashakti dkk. (2017) yang menunjukkan bahwa kompensasi karyawan 
berpengaruh positif terhadap turnover intention. Tangthong et al. (2014) mengidentifikasi kompensasi sebagai faktor signifikan yang mempengaruhi niat karyawan untuk tinggal. Widayati \& Yunia (2016) menemukan bahwa kompensasi berpengaruh positif terhadap turnover intention, hal ini menunjukan bahwa semakin besar kompensasi yang diterima, niat untuk keluar dari pekerjaan akan berkurang karena karyawan merasa dihargai dengan kebutuhannya yang dapat terpenuhi, begitu juga sebaliknya.

Hasil hipotesis dalam penelitian ini menunjukkan bahwa lingkungan kerja fisik memoderasi berpengaruh stres kerja terhadap turnover intention pada Hotel Mercure Legian-Bali. Dimana efek moderasi yang dihasilkan adalah memperkuat hubungan, dengan kata lain apabila terdapat lingkungan kerja fisik maka pengaruh stres kerja terhadap turnover intention pada Hotel Mercure Legian-Bali. akan semakin diperkuat sehingga hipotesis ketiga diterima.

Hasil penelitian ini sejalan dengan Hasil penelitian yang dilakukan oleh Syahronica \& Ruhana (2015) bahwa stres merupakan faktor dominan yang mempengaruhi turnover intention. Irvianti \& Verina (2015) dalam penelitiannya menunjukkan stres kerja, dan lingkungan kerja secara parsial berpengaruh positif terhadap turnover intention.

Sahlan (2016) menunjukkan bahwa stres kerja karyawan perlu dikelola oleh seorang pimpinan perusahaan agar potensi-potensi yang merugikan perusahaan dapat diatasi. Dewi \& Wibawa (2016) menunjukkan bahwa tingkat stres kerja yang tinggikan berdampak pada turnover intention yang meningkat. Lingkungan pekerjaan fisik memberikan efek positif dari stres kerja yang tinggi terhadap turnover intention. Parvaiz et al. (2015) pun memberi petunjuk stres kerja mempunyai hubungan positif dengan turnover intention yang dimoderasi oleh lingkungan kerja fisik, bila pegawai mengalami stres kerja serta tak mempunyai mekanisme yang sesuai agar mengurangi stres kerja yang dipengaruhi oleh lingkungan kerja fisiknya.

Hasil hipotesis dalam penelitian ini menunjukkan bahwa lingkungan kerja fisik memoderasi berpengaruh kompensasi karyawan terhadap turnover intention pada Hotel Mercure Legian-Bali. Dimana efek moderasi yang dihasilkan adalah memperkuat hubungan, dengan kata lain apabila terdapat lingkungan kerja fisik maka pengaruh kompensasi karyawan terhadap turnover intention pada Hotel Mercure Legian-Bali. akan semakin diperkuat sehingga hipotesis keempat diterima. Hasil penelitian ini sejalan dengan Hasil penelitian yang dilakukan oleh Aarakit \& Kimbugwe (2015) mengatakan bahwa peran moderasi lingkungan kerja fisik pada hubungan kompensasi karyawan yang berpengaruh positif terhadap turnover intention.

Khikmawati (2015) menyebutkan faktor lain yang signifikan negatif mempengaruhi turnover intention adalah lingkungan kerja. Penelitian Fatkhurahman Arliansyah (2016) juga memperlihatkan adanya pengaruh yang negatif antara kompensasi dan turnover intention yang di pengaruhi oleh lingkungan kerja fisik. 
Khikmawati (2015) menyebutkan faktor lain yang signifikan negatif dimana faktor yang mempengaruhi turnover intention adalah lingkungan kerja fisik. Putrianti (2014) yang membuktikan bahwa kompensasi berpengaruh negatif dan signifikan terhadap turnover intention.

Hal ini didukung oleh penelitian Yunita, \& Putra (2015) yang menyebutkan turnover intention dipengaruhi secara signifikan oleh faktor lingkungan kerja. Oleh karena itu, untuk mengisi kesenjangan, penelitian ini mempertimbangkan lingkungan kerja sebagai moderator untuk menyelidiki lebih lanjut hubungan antara kompensasi dan turnover intention.

\section{SIMPULAN}

Berdasarkan hasil pembahasan tersebut, maka dapat disimpulkan bahwa hasil penelitian ini memberikan bukti pada pengembangan sumber daya manusia khususnya mengenai stres kerja, kompensasi karyawan, lingkungan kerja fisik dan turnover intention.

Hasil penelitian ini memberikan dukungan empiris dan dapat dinyatakan memperkuat hasil-hasil studi terdahulu. Dapat juga memberikan pemahaman bahwa stres kerja, kompensasi karyawan dan lingkungan kerja fisik secara nyata dapat mempengaruhi turnover intention, ketika stres kerja dan kompensasi karyawan yang dirasakan oleh karyawan meningkatkan maka dapat memperkuat turnover intention, lingkungan kerja fisik yang dirasakan oleh karyawan menjadi semakin kuat sehingga berpotensi meningkatkan turnover intention.

Hasil penelitian ini dapat menjadi referensi bagi perusahan Hotel MercureLegian Bali yang dapat menjadi salah satu acuan bagi peneliti lainnnya yang ingin meneliti mengenai pengaruh stres kerja dan kompensasi karyawan terhadap turnover intention dengan lingkungan kerja fisik sebagai variabel moderasi.

\section{REFERENSI}

Aarakit, S. M., \& Kimbugwe, F. K. (2015). Moderating Effect of Organizational Environment on Intrapreneurial Orientation and Firm Performance. Global Advanced Research Journal of Management and Business Studies, 4(7), 285290. Retrieved from http://garj.org/garjmbs/index.htm

Allisey, A. F., Noblet, A. J., Lamontagne, A. D., \& Houdmont, J. (2014). Testing a Model of Officer Intentions to Quit: The Mediating Effects of Job Stress and Job Satisfaction. Criminal Justice and Behavior, 41(6), 751-771. https://doi.org/10.1177/0093854813509987

Arin Dewi Putrianti, D. H. \& M. D. M. (2014). Pengaruh Kompensasi dan Motivasi Terhadap Turnover Intention (Studi Pada Karyawan PT. TIKI Jalur. Jurnal Administrasi Bisnis (JAB), 12(2), 1-9. 
Arshadi, N., \& Damiri, H. (2013). The Relationship of Job Stress with Turnover Intention and Job Performance: Moderating Role of OBSE. Procedia - Social and Behavioral Sciences, 84(2003), 706-710. https://doi.org/10.1016/j.sbspro.2013.06.631

Bagus, I., Swambawa, G., \& Rahyuda, A. G. (2016). PENGARUH KOMPENSASI , LINGKUNGAN KERJA DAN PERCEIVED ORGANIZATIONAL SUPPORT ( POS ) TERHADAP RETENSI KARYAWAN Fakultas Ekonomi dan Bisnis Universitas Udayana ( Unud), Bali , Indonesia PENDAHULUAN SDM mempunyai tugas yang besar dalam kinerja sebuah perusa. 5(2), 810-837.

Bibi, P., Ahmad, A., \& Majid, A. H. A. (2018). The impact of training and development and supervisors support on employees retention in academic institutions in Pakistan: The moderating role of the work environment. Gadjah Mada International Journal of Business, 20(1), 113-131. https://doi.org/10.22146/gamaijb.24020

Dewi, C., \& Wibawa, I. (2016). Pengaruh Stres Kerja Dan Motivasi Kerja Terhadap Kinerja Karyawan Pada Pt. Bank Bpd Bali Cabang Ubud. E-Jurnal Manajemen Universitas Udayana, 5(12), 7583-7606.

Dharma, C. (2013). Jurnal ekonomi dan bisnis jurusan administrasi niaga politeknik negeri medan. Hubungan Antara Turnover Intention Dengan Komitmen Organisasional Di PT X Medan, 1(2).

Feng, Mingming, X. "Abby" W. \& J. S. S. (2010). Monetary compensation, workforce-oriented corporate social responsibility, and firm performance. (Unit 07), 1-5.

Haryanti, A. R. B. S. dan K. (2014). HUBUNGAN KOMITMEN ORGANISASI DAN KEPUASAN KERJA DENGAN INTENSI TURNOVER PADA KARYAWAN BIDANG PRODUKSI CV. X. Psikodimensia, 13(1), 98-114.

Johartono, \& Widuri, R. (2014). Turnover Intention Karyawan Kantor Konsultan Pajak Di Surabaya. Tax \& Accounting Review, 3(2), 1-13.

Kadek, N., Yunita, L., \& Putra, M. S. (2015). Kerja Terhadap Turnover Intention. 4(5), 1166-1185.

Khikmawati, R. (2015a). PENGARUH KEPUASAN KERJA DAN LINGKUNGAN KERJA TERHADAP TURNOVER INTENTION PRAMUNIAGA DI PT CIRCLEKA INDONESIA UTAMA CABANG YOGYAKARTA. Acta Universitatis Agriculturae et Silviculturae 
E-Jurnal Manajemen, Vol. 9, No. 5, 2020 : 1758-1777

Mendelianae Brunensis, 16(2), 39-55. https://doi.org/10.1377/hlthaff.2013.0625

Khikmawati, R. (2015b). PENGARUH KEPUASAN KERJA DAN LINGKUNGAN KERJA TERHADAP TURNOVER INTENTION PRAMUNIAGA DI PT CIRCLEKA INDONESIA UTAMA CABANG YOGYAKARTA. Acta Universitatis Agriculturae et Silviculturae Mendelianae Brunensis, 16(2), 39-55. https://doi.org/10.1377/hlthaff.2013.0625

Laksmi, Irvianti, D., \& Verina, R. E. (2015). Karyawan Pada Pt Xl Axiata Tbk Jakarta. 2, 117-126.

Luh, N., Sri, M., \& Sudibia, G. A. (2015). FINANSIALTERHADAP KEPUASAN KERJA DAN TURNOVER INTENTION: ( STUDI PADA KARYAWAN KONTRAK DI BALI DYNASTY RESORT) Fakultas Ekonomi dan Bisnis Universitas Udayana ( Unud), Bali, Indonesia Fakultas Ekonomi dan Bisnis Universitas Udayana ( Unud ), Bali, In. 4(4), 1047-1066.

Mehta, M., Kurbetti, A., \& Dhankhar, R. (2014). Review Paper - Study on Employee Retention and Commitment. International Journal of Advance Research in Computer Science and Management Studies, 2(2), 154-164.

Mustika, S., \& Rahardjo, K. (2017). PENGARUH PERCEIVED ORGANIZATIONAL SUPPORT TERHADAP EMPLOYEE ENGAGEMENT DAN ORGANIZATIONAL CITIZENSHIP BEHAVIOUR (Studi pada Staf Medis Rumah Sakit Lavalette Malang). Jurnal Administrasi Bisnis S1 Universitas Brawijaya, 47(1), 9-15.

Nurul Ikhsan Sahlan, P. A. M. \& I. T. (2015). PENGARUH LINGKUNGAN KERJA, KEPUASAN KERJA DAN KOMPENSASI TERHADAP KINERJA KARYAWAN PADA PT. BANK SULUT CABANG AIRMADIDI. 3(1), 52-62.

Parvaiz, L., Saba, B., Ambar, K., \& Yasir, A. F. (2015). Impact of Stressors (Role conflict, Role overload, Leadership Support and Organizational Politics) on Job Stress and its Subsequent Impact on Turnover Intention. International Journal of Business and Management Invention, 4(10), 52-63.

Pepra-Mensah, J., Adjei, L. N., \& Yeboah-Appiagyei, K. (2015). The Effect of Work Attitudes on Turnover Intentions in the Hotel Industry: The Case of Cape Coast and Elmina (Ghana). European Journal of Business and ManagementOnline), 7(14), 2222-2839. 
Qureshi, M. I., Iftikhar, M., Abbas, S. G., Hassan, U., Khan, K., \& Zaman, K. (2013). Relationship between job stress, workload, environment and employees turnover intentions: What we know, what should we know. World Applied Sciences Journal, 23(6), 764-770. https://doi.org/10.5829/idosi.wasj.2013.23.06.313

Rumada, G., \& Utama, I. (2013). Pengaruh Kompensasi, Kepemimpinan, dan Lingkungan Kerja Fisik Terhadap Kepuasan Kerja Karyawan Hotel Taman Harum Ubud Gianyar. E-Jurnal Manajemen Universitas Udayana, 2(1).

Sandi, F. M. (2014). ANALISIS PENGARUH KOMPENSASI DAN JOB INSECURITY TERHADAP TURNOVER INTENTION ( Studi Pada Guru SDIT Asy-Syaamil Bontang ).

Sito, L., \& Irvianti, D. (2014). CITIZENSHIP BEHAVIOR TERHADAP KEPUASAN KERJA DI FORD JAKARTA PUSAT Stefhani ; Laksmi Sito Dwi Irvianti. Msdm, Vol. 5 No., 39-48.

Subagyo, A. (2014). PENGARUH LINGKUNGAN KERJA DAN SELF EFFICACY TERHADAP KOMITMEN ORGANISASIONAL DOSEN POLITEKNIK NEGERI SEMARANG. Orbith, 10(1), 74-81.

Sudharma, I. G. A. R. P. I. dan I. N. (2013). PENGARUH GAYA KEPEMIMPINAN, BUDAYA ORGANISASI DAN LINGKUNGAN KERJA FISIK TERHADAP DISIPLIN KERJA KARYAWAN DINAS PERTANIAN TANAMAN PANGAN DAN HORTIKULTURA KOTA DENPASAR. Journal of Chemical Information and Modeling, 53(9), 16891699. https://doi.org/10.1017/CBO9781107415324.004

Suwandana, M. Y. P. I. G. M. (2017). KOMITMEN ORGANISASIONAL TERHADAP TURNOVER INTENTION PADA GRAND MIRAGE RESORT \& THALASSO BALI. E-Journal Manajemen Unud, 6(12), 65616591.

Syahronica, G. (2015). PENGARUH KEPUASAN KERJA DAN STRES KERJA TERHADAP TURNOVER INTENTION (Studi Pada Karyawan Departemen Dunia Fantasi PT Pembangunan Jaya Ancol, Tbk). Jurnal Administrasi Bisnis, 20(1), 1-6.

Tangthong, S. (2014). The Effects Of Human Resource Management Practices On Employee Retention In Thailand's Multinational Corporations. International Journal of Economics, Commerce and Management, 2(10), 1-30.r 
E-Jurnal Manajemen, Vol. 9, No. 5, 2020 : 1758-1777

Widayati, C., \& Yunia, Y. (2017). Pengaruh Kompensasi Dan Budaya Organisasi Terhadap Turnover Intention. Jurnal Manajemen, 20(3), 387-401. https://doi.org/10.24912/jm.v20i3.14 